\title{
Understanding young people's barriers to sexually transmitted disease screening and meeting their needs: A focus group study
}

\author{
Bettina Trettin * Tine Vestergaard, Anette Stensgaard \\ Department of Dermatology and Allergy Centre, Odense University Hospital, Odense, Denmark
}

Received: February 25, 2015

Accepted: March 24, 2015

Online Published: April 10, 2015

DOI: $10.5430 /$ jnep.v5n6p81

URL: http://dx.doi.org/10.5430/jnep.v5n6p81

\begin{abstract}
Background: Chlamydia is the most common bacterial sexually transmitted disease (STD) in adolescents, and may have severe consequences such as pelvic infections, cervical cancer and infertility if left untreated. Studies have determined that young people have several barriers towards getting tested for STD. This study seeks not only to address the barriers to STD testing but also to understand them and thereby improve the quality of care in an outpatient clinic and increase screening rates.

Methods: The study uses a phenomenological, hermeneutical approach through qualitative interviews. Four focus groups with a total of 22 participants in the age between 16-25 years were conducted for this study.

Results: It was found that testing for STD is still associated with stigmatization and our findings indicate that testing for STD should undergo normalization. At the same time health care providers face a major challenge in advising young people due to the lack of knowledge and the fear of being reprimanded.

Conclusions: None of the participants were aware of our clinic. Changes were made in the outpatient clinic to consider the needs of the young people. We implemented non-invasive screening methods for those attending asymptomatic screening, introduced both nurse-led consultations and anonymous counseling regarding STDs and testing.
\end{abstract}

Key Words: Qualitative research, Barriers, Sexually transmitted diseases, Stigma

\section{INTRODUCTION}

Sexually transmitted diseases (STDs) are a public health problem among both adolescents and young adults between the ages of $15-25$ years. $25.841 \%$ were tested positive for Chlamydia in Denmark in 2013, and the incidence of Gonorrhea is increasing rapidly. ${ }^{[1,2]}$ Every fourth person in Denmark will before the age of 25 test positive for STD. However, the number of patients attending screening is falling in Denmark and approximately $50 \%$ of STDs are asymptomatic; therefore, it is important to increase the screening rate among this group.
The most common STD among this group is Chlamydia. In most cases, Chlamydia infections are asymptomatic, but may have severe consequences such as pelvic infections, cervical cancer and infertility if left untreated. ${ }^{[3,4]}$ Screening for, or being diagnosed with an STD is often associated with embarrassment, stigma and anxiety. ${ }^{[5-7]}$ Existing research shows that young adults feel exposed when getting tested for an STD, because they worry it will lead to a negative impact on their social status. ${ }^{[8,9]}$ Other studies also point out, that young people choose, not to get tested due to the lack of knowledge about STDs and argue that young people do

*Correspondence: Bettina Trettin; Email: bettina.trettin@rsyd.dk; Address: Department of Dermatology and Allergy Centre, Odense University Hospital, Odense, Denmark.

Published by Sciedu Press 
not perceive themselves at risk of contracting an STD. ${ }^{[10-12]}$ However, the above mentioned studies did not include implications on how to address these barriers, and most previous research pertains to young people who were recruited from a sexual health clinic. ${ }^{[13-15]}$ There has not been similar research exploring the feelings, attitudes and views on screening for STD in Denmark. Scandinavia is considered to have a liberal attitude towards sexuality where love and intimacy are openly discussed between young people. ${ }^{[16]}$

\section{METHOD}

\subsection{Purpose of the study}

This study aimed to investigate the young people at risk of contracting an STD, but who have not attended a sexual health clinic, in order to determine their perspectives on STD screening. It seeks to illuminate the existing barriers towards testing and to gain a better understanding of them, in order to meet the needs of the young people and to increase the number of asymptomatic patients attending screening.

\subsection{Study questions}

In order to meet the aim of our study, this study posed two research questions: (1) what thoughts and expectations do the young ascribe to the fact that they are to be tested for sexually transmitted diseases? and (2) which factors could influence their decision to get tested?

\subsection{Study design}

The study used a phenomenological, hermeneutical approach through focus group interviews to generate a depth of understanding of what young people think about screening for STDs. ${ }^{[1]}$ Focus group method can be an strategy for studying community strengths and potential interventions that have local meaning and utility. ${ }^{[18]}$

The study was conducted in Denmark, in a university city with approximately 195,400 citizens. All authors are healthcare professionals at the sexual health clinic, which offers free testing for STDs. Approximately 93\% of all Chlamydia analysis in Denmark were conducted by general practitioners, and only $7 \%$ were conducted in a hospital setting. ${ }^{[1]}$

\subsection{Sample}

This study included four focus groups, consistent of three to eight participants in each (see Table 1), the interviews lasted from 82 minutes to 102 min with an average of 94 minutes. The focus groups were arranged by age and gender to increase trust and thereby create a setting, were the participants felt safe to speak freely and openly. Participants were recruited from a university and a local high school, and received both verbal and written information before the interviews. All participants signed a written consent form before 82 the interview began and were guaranteed full anonymity. In Denmark qualitative interviews do not require the approval of an ethics committee. One of the four interviews was conducted in a private conference room, located at the hospital, the rest were conducted in private rooms at the educational institute of the participants.

Table 1. Classification of focus groups

\begin{tabular}{lll}
\hline Group & Composition & Median Age in years (range) \\
\hline 1 & 4 females & $21(19-23)$ \\
2 & 3 males & $21(19-23)$ \\
3 & 7 females & $18(17-19)$ \\
4 & 8 males & $17.5(16-19)$ \\
\hline
\end{tabular}

\subsection{Interviews}

The first author conducted the interviews and used a semistructured interview guide developed for this study, addressing the following topics: Feelings and attitudes towards testing, knowledge about STDs, suggestions and ideas of the ideal testing scenario, and how to address the target group further. Every interview was initiated with a brainstorming session related to STD and ended with more specific questions. The interaction between the participants in focus groups is considered important ${ }^{[19]}$ therefore the sessions were planned to include several group exercises and the interviewer aimed for minimal intervention in the beginning of each session. However, the interviewer needed to ask clarifying questions, such as "Try to explain that?" or "Can you give me an example?" Also the interviewer made sure to involve all participants in the session, if necessary. An observer was present during the interviews to take notes and document the interaction between the participants. All interviews were recorded and transcribed into the Nvivo software.

\subsection{Data analysis}

The design of the study was qualitative and took a phenomenological-hermeneutical approach. The process of the analysis interpretation was inspired by Paul Ricoeur's Philosophy of Interpretation. ${ }^{[20]}$ This process is an ongoing movement between three levels: naive reading, structural analysis and critical interpretation. Naive reading: The entire text was read several times to get a naive understanding of the meaning in the text and to grasp a sense of the whole. Structural analysis: The text was split up into meaning units by gathering quotes across the data, which expressed what was said in the text. Through the dialectical process between explanation and understanding, themes as well as related subthemes emerged, an example is provided in Table 2 . The aim of the critical interpretation was to draw a deeper understanding of the appearing themes. Therefore themes were discussed in relation to other research and relevant theory, which opened the text even further.

ISSN 1925-4040 E-ISSN 1925-4059 
Table 2. Examples of analysis

\begin{tabular}{lll}
\hline Meaning units - what is said & Units of significance - what it speaks about & Themes and subthemes \\
\hline "To lie there and spread your legs (pelvic & The girls are not just afraid of having a pelvic & Barriers towards testing \\
examination red.) it’s really... I certainly wouldn't & examination because of the pain they expect, & Insecurity \\
$\begin{array}{l}\text { like it. You're also afraid that they will judge you in } \\
\text { some way... yeah the fear of having to lie there.” }\end{array}$ & $\begin{array}{l}\text { they also feel exposed and unsecure of their } \\
\text { body. }\end{array}$ & Fear \\
\hline
\end{tabular}

\section{Results}

The interviews and following analysis identified three main themes described below. All of the themes had embarrassment as a common feature and are therefore related to each other.

\subsection{Barriers towards testing}

The barriers towards getting tested for STDs were many and are illustrated in Figure 1. The participants wanted to keep testing for STD a secret, and involve as few people as possible in the process. Taking contact to a general practitioner (GP) was described as inconvenient, because of the waiting time to get an appointment and having to explain a second party, like a secretary, that they would like to get tested. This contributed to the fact, that the participants found it difficult, to take the initiative to get tested. One of the participants said:

I myself have contacted my doctor regarding this and it seems one becomes that... (changes her tone of voice) Why do you want this? Why do you want a check-up? For what? (the others joined in) You just have a suspicion and just wants a check-up, but it seems that you have to justify this.

This indicated that the participants felt stigmatized when they contacted their GP and that they had to argue for the testing. The participants would like an alternative way to apply for testing, with no explanation needed. None of the participants were aware of the sexual health clinic in Odense and the option of "walk-in" without any appointment needed. Furthermore findings indicated that young people may not get tested unless they have obvious symptoms of an STD:

It could very well be..., at least I think, speaking for myself, if it was just a minor symptom, I would wait for it to disappear. If you just had unprotected sex once, probably nothing will happen, you don't get tested, I could imagine a lot of people think like that. . It was just once, nothing will happen.

In theory the participants knew that they could have an STD without having any symptoms, but they stated that they would probably wait to get tested until symptoms would appear. They did not see themselves as being at risk of getting an STD and they seemed to be subjected to a feeling of immortality. The girls were more worried about an unwanted pregnancy and they all expressed an insecurity of when to get tested if necessary and a concern about wasting the time of health professionals. Both males and females were afraid of the examination for STDs. For the youngest female participants undergoing a gynecological examination was a barrier: "Having to lie there and spread your legs, that's really... I wouldn't like it anyway. You're also afraid that they (healthcare personal red.) could judge you in some way... yeah the fear of having to lie there." They were afraid that the examination itself would hurt, and at the same time they would feel exposed, and insecure about their bodies. They expressed concerns about how they would look different and wrong compared to others, and that healthcare personal would notice that. Also the more inexperienced females did not know what to expect; they believed that a gynecological examination took up to one hour to perform.

The boys were worried about the urethral swabs: "I still remember these scary stories, with pretty offensive test methods... where you have to get a swab into (urethra red.)...' None of the male participants felt safe having to get tested with a swab, and this way of testing created fear and the expectation of great pain.

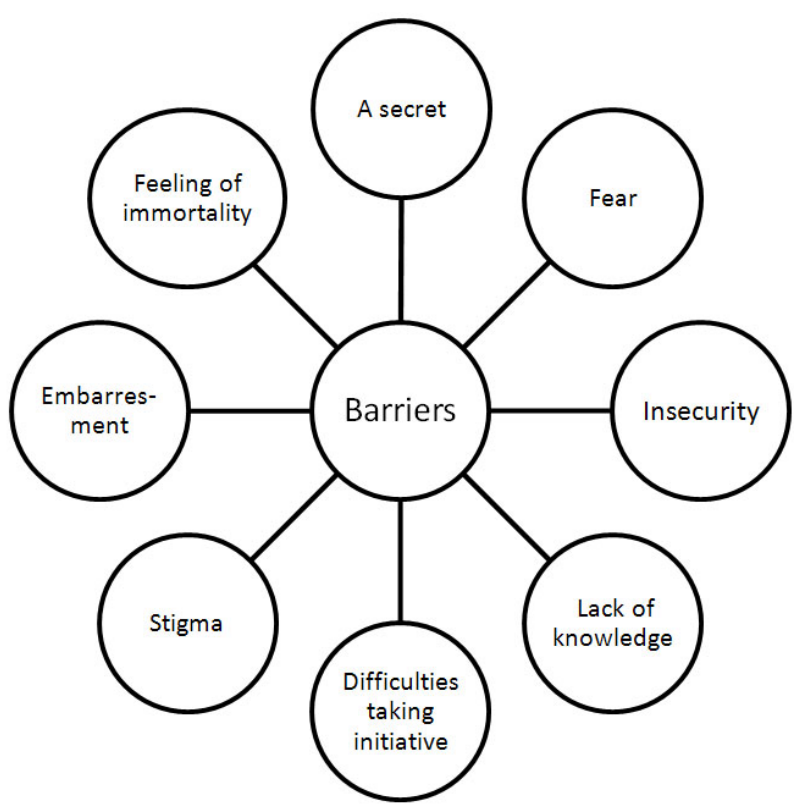

Figure 1. Presents an overview of the barriers related to testing 


\subsection{Wish of detachment versus lack of knowledge}

All participants would like to get more knowledge and information about STDs, but not in the actual testing setting. They felt it would be humiliating if healthcare workers started to advise them about safe sex. This kind of advice was considered as finger pointing and correcting, which the participants considered to be the last thing they needed: "Well you (health care professionals red.) can't just run after them and say: 'you've got to remember to use a condom', nothing will come out of that." Another participant agreed:

It's probably not a cool situation to get tested at all, I would probably avoid that another time, but I don't need, when I have been tested and tested positive for you to sit down and talk all educational and say: "that was not good dude".

It seems that the participants wanted the advice and guidance while they were healthy, not when they got an STD. In that way they tried to distance themselves from personal advice. At the same time, our study found, that these young people have a substantial lack of knowledge regarding STDs: "Gonorrhea and syphilis I don't know what that is... again we've talked about something with some bubbles?" "Are genital warts the same as herpes?" "You can only get HIV if you switch blood." The participants lacked knowledge both in regards to the symptoms of different STDs and their mode of transmission and treatment. This creates a dilemma considering they do not want advice in a clinical setting, which can create a professional challenge for the healthcare workers.

\subsection{Making testing an ordinary thing}

Despite the above mentioned barriers and wish for detachment, all of the participants preferred testing for STDs to be a normal routine; something all young people have to do. That would reduce the embarrassment and they would not feel as stigmatized. "Yeah then it won't be something like, oh well I have to see the doctor, it's a personal matter... it will be more like, I have to see the doctor, it's that routine check you know?" At the same time the participants encouraged that testing should be more available and that health care workers should seek to undermine the barriers towards testing: "It's just a matter of breaking down that... make something good out of it, a good atmosphere. Maybe not too old people, trying to recruit people to getting tested... you'll get, I don't know... beer tickets." Moreover, all participants called for more humor and a more relaxed attitude towards testing. This would make it easier for them to get tested and to talk about STDs. At the same time, the participants needed to feel invited, welcome and more importantly, accepted:

Yes, this issue of the solemnity (gravity of testing), has to be minimized, get it down to earth. It has to be something normal. You don't want to be the outsider who does it (get tested red.). You don't have to talk to anyone, just come as you are.

The participants made it clear that testing for STDs has to be easily available and they agreed that it should be verbalized to undermine the stigma and the many barriers, by making testing an ordinary thing.

\section{Discussion}

Previous research has identified many barriers towards testing for STDs similar to our findings. These include stigma, shame, lack of knowledge, and method of specimen collection. ${ }^{[6,8,11,21]}$ These barriers seem to persist regardless of cultural background and geographic location. Young people seem to be afraid of getting tested, not only because of the related stigma, but also because of the specimen collection and physical examination. Our study points out that young people do not know what to expect. This increases insecurity and fear, and results in the rejection of STD testing. Male participants in our study were aware of the possibility of urine sampling and wondered why the swab still existed. The females agreed, that they would consider getting tested if they could avoid a gynecological examination. This information needs to be taken into consideration when evolving new practices with the aim of increasing screening rates.

All participants liked the idea of getting tested without having to involve their general practitioner, whom they may have known since early childhood. Furthermore, research indicates that general practitioners seem to have barriers against offering Chlamydia screening if the patient's problem is not related to a sexual issue ${ }^{[13]}$ as well as a lack of time. ${ }^{[22]}$ This conflicts with the fact, that young people want screening for STDs to be an ordinary thing, which is substantiated by other studies. ${ }^{[23-26]}$ Participants in this study also wished for a more relaxed attitude towards testing. Richardson, ${ }^{[6]}$ argues that the aim of educating young people in regard to Chlamydia screening should be to remove the seriousness and scariness aspects of Chlamydia testing and the test itself, this could help reduce stigma and normalize testing. Our participants did not want any finger pointing or discussions regarding their sexuality or behavior. Neither did they want the health care workers to inform them about STDs and transmission modes. Due to their lack of knowledge this creates a challenge for health care workers.

Christianson ${ }^{[23]}$ had similar findings in her research and encourages focusing on quick and easy testing rather than extensive counseling. Keeping an open mind and being flexible in counseling would be preferable. Balfe et al. ${ }^{[27]}$ argue, that health care professionals need to monitor their own in- 
teraction style with patients, and that they should not use any moral surveillance methods in their interaction. Also, Hogan ${ }^{[28]}$ emphasizes that a non-judge-mental attitude, when offering Chlamydia screening, could help minimizing barriers such as embarrassment.

\section{Critical comments}

This study has some limitations. We only included four focus groups, since sampling turned out to be more challenging then estimated, which only points out how STDs are still related to stigma and embarrassment. The number of only four focus groups can, however, be an adequate number when working with particular populations, ${ }^{[19]}$ as we did in our study. The study did not include any demographic data, which could have been interesting, but not necessarily relevant in relation to our research question. The strength of our study is, that the participants were recruited from a local high school and a university, not from a sexual health clinic. This enabled us to include the frank perspectives, thoughts and ideas of these young people who had not visited such a clinic, but are at risk of contracting an STD.

\section{CONCLUSIONS AND IMPLiCATIONS}

This study found that a young person does not want to be the outsider who takes a test and that testing is still related to fear, stigma and embarrassment. The aim was to meet the needs of the young people and increase the screening rate. The "walkin" clinic at the university hospital, changed its practice in consideration of the findings: The young people were given the opportunity to call anonymously for counseling for STDs and testing. Furthermore opening hours were expanded, to increase the ease of access. Self-collected vaginal swabs for females and urine samples for males were implemented for those attending asymptomatic screening. Since a majority of patients no longer had to undergo a gynecological examination, nurse-led consultations for asymptomatic screening in females and symptomatic screening in males were in- troduced. Nurses were trained in diagnostic and treatment regarding STD's. Communication skills were discussed and moderated with the aim of removing any finger-pointing and reducing stigma as well as embarrassment. Our study made it clear that young people have to overcome many barriers before attending our clinic; therefore they needed to feel welcome, which is why we adopted a new slogan: "Come as you are." The intention was to create a more welcoming atmosphere and to indicate that everyone is welcome and at the same time minimize the gravity of testing.

Since none of the participants in our study knew about the "walk-in" clinic, it was necessary to advertise. We created a new homepage, a Facebook account and distributed post cards and condoms, with our logo. General practitioners from relevant areas were invited and received information about the "walk-in" clinic and its offers. A young person, from outside the clinical setting was hired to administrated our Facebook account in order to establish an informal tone with a sense of humor. The participants in our study agreed to give us feedback by e-mail and comment on our new measures in order to adjust them if necessary.

During a period of 12 months these implications contributed to an increase of $35 \%$ rise in the number of patients who visited the clinic for the first time. This confirms the need not only to investigate the barriers towards screening for STDs, but also to address them by improving clinical practice in consideration of those barriers.

\section{ACKNOWLEDGEMENTS}

We thank the young people who agreed to participate in this study. Also The Department of Dermatology and Allergy Centre, Odense University Hospital has received economic support from MEDA in the form of an educational grant.

\section{CONFLicts OF INTEREST Disclosure}

The authors declare that there is no conflict of interest statement.

\section{REFERENCES}

[1] SSI. Klamydia 2013, 2014. Available from: http: //www.ssi.dk/Aktuelt/Nyhedsbreve/EPI-NYT/2014/ Uge $\% 2036 \% 20-\% 202014$. aspx

[2] SSI. Gonoré 2013, 2014. Available from: http: //www.ssi.dk/Aktuelt/Nyhedsbreve/EPI-NYT/2014/ Uge $\% 2035 \% 20-\% 202014$. aspx

[3] Skala SL, Secura GM, Peipert JF. Factors associated with screening for sexually transmitted infections. American Journal of Obstetrics \& Gynecology. 2012; 206(4): 324.e1-6. PMid:22464074 http://dx.doi.org/10.1016/j.ajog.2012.02.020

Published by Sciedu Press
[4] Baraitser P, Alexander S, Sheringham J. Chlamydia trachomatis screening in young women. Current Opinion in Obstetrics \& Gynecology. 2011; 23(5): 315-20. PMid:21897235 http://dx.doi.o $\mathrm{rg} / 10.1097 / \mathrm{GCO} .0 \mathrm{~b} 013 \mathrm{e} 32834 \mathrm{ac} 776$

[5] Brugha R, Balfe M, Jeffares I, et al. Where do young adults want opportunistic chlamydia screening services to be located? J Public Health (Oxf). 2011; 33(4): 571-8. PMid:21486871 http://dx. doi . org/10.1093/pubmed/fdr028

[6] Richardson D, Maple K, Perry N, et al. A pilot qualitative analysis of the psychosocial factors which drive young people to decline chlamydia testing in the UK: implications for health promotion and 
screening. Int J STD AIDS. 21. England; 2010; 187-90.

[7] Cunningham SD, Kerrigan DL, Jennings JM, et al. Relationships between perceived STD-related stigma, STD-related shame and STD screening among a household sample of adolescents. Perspect Sex Reprod Health. 2009; 41(4): 225-30. PMid:20444177 http://dx.doi.org/10.1363/4122509

[8] Balfe M, Brugha R, O'Connell E, et al. Why don't young women go for Chlamydia testing? A qualitative study employing Goffman's stigma framework. Health, Risk \& Society. 2010; 12(2): 131-48. http://dx.doi.org/10.1080/13698571003632437

[9] Ford CA, Jaccard J, Millstein SG, et al. Young adults' attitudes, beliefs, and feelings about testing for curable STDs outside of clinic settings. Journal of Adolescent Health. 2004; 34(4): 266-9. PMid:15040995 http://dx.doi.org/10.1016/j.jadohealth. 2003.07.013

[10] Christianson M, Johansson E, Emmelin M, et al. "One-night stands" risky trips between lust and trust: qualitative interviews with Chlamydia trachomatis infected youth in north Sweden. Scandinavian Journal of Public Health. 2003; 31(1): 44-50. http://dx. doi .org/10.10 $80 / 14034940210134158$

[11] Sanders LS, Nsuami M, Cropley LD, et al. Reasons given by high school students for refusing sexually transmitted disease screening. Health Education Journal. 2007; 66(1): 44-57. http://dx.doi.o rg/10.1177/0017896907073784

[12] Chaudhary R, Heffernan CM, Illsley AL, et al. Opportunistic screening for Chlamydia: a pilot study into male perspectives on provision of Chlamydia screening in a UK university. J Public Health (Oxf). England; 2008; 466-71.

[13] McNulty CA, Freeman E, Bowen J, et al. Barriers to opportunistic chlamydia testing in primary care. The British journal of general practice: The journal of the Royal College of General Practitioners. 2004; 54(504): 508-14.

[14] Norton J. Sexual health services: reaching young people. Practice Nurse. 2010; 39(6): 36-41.

[15] Balfe M, Brugha R. Disclosure of STI testing activities by young adults: the influence of emotions and social networks. Sociology of Health \& Illness. 2010; 32(7): 1041-58. PMid:20937054 http://dx.doi.org/10.1111/j.1467-9566.2010.01281.x

[16] Traeen B, Lewin B, Sundet JM. The real and the ideal: Gender differences in heterosexual behaviour among Norwegian adolescents. Journal of Community \& Applied Social Psychology. 1992; 2(4): 227-37. http://dx.doi.org/10.1002/casp. 2450020402

[17] Miller WR. Qualitative research findings as evidence: utility in nursing practice. Clinical Nurse Specialist: The Journal for Advanced Nursing Practice. 2010; 24(4): 191-3. PMid:20526118 http://dx.doi.org/10.1097/NUR.0b013e3181e36087
[18] Stevens PE. Focus groups. Public health nursing. 1996; 13(3): 170-6. Stevens PE. Focus groups. Public health nursing. 1996; 13(3): 170-6. http://dx.doi.org/10.1111/j.1525-1446.19 96.tb00237.x

[19] Kitzinger J. The methodology of focus groups: the importance of interaction between research participants. Sociology of Health \& Illness. 1994; 16(1): 103-21. http://dx.doi.org/10.1111/146 7-9566. ep11347023

[20] Ricoeur P. Fortolkningsteori. Kbh: Vinten; 1979; 222.

[21] Backonja U, Royer HR, Lauver DR. Young Women's Reasons to Seek Sexually Transmitted Infection Screening. Public Health Nursing. 2014. PMid:24766580 http://dx.doi.org/10.1111/phn.121 25

[22] Hardwick D, McKay A, Ashem M. Chlamydia screening of adolescent and young adult women by general practice physicians in Toronto, Canada: baseline survey data from a physician education campaign. Canadian Journal of Human Sexuality. 2007; 16(34): 63-75. PMid:20487408 http://dx.doi.org/10.1111/j.1 471-6712.2009.00762. $\mathrm{x}$

[23] Christianson M, Berglin B, Johansson EE. "It should be an ordinary thing"- a qualitative study about young people's experiences of taking the HIV-test and receiving the test result. Scandinavian Journal of Caring Sciences. 2010; 24(4): 678-83. PMid:20487408 http://dx.doi.org/10.1111/j.1471-6712.2009.00762.x

[24] De Cock KM, Johnson AM. From exceptionalism to normalisation: a reappraisal of attitudes and practice around HIV testing. British Medical Journal. 1998; 316: 290-2. PMid:9472517 http: //dx.doi.org/10.1136/bmj.316.7127.290

[25] Baraitser P, Alexander S, Sheringham J. Chlamydia trachomatis screening in young women. Current Opinion in Obstetrics and Gynecology. 2011; 23(5): 315-20. PMid:21897235 http://dx . doi .o $\mathrm{rg} / 10.1097 / \mathrm{GCO} .0 \mathrm{~b} 013 \mathrm{e} 32834 \mathrm{ac} 776$

[26] McMillan LE, Norman JE, Murray K, et al. Factors influencing women's views on the acceptability and experience of being opportunistically screened for Chlamydia trachomatis in hospital settings. International journal of STD \& AIDS. 2006; 17(12): 821-5. PMid:17212859 http://dx.doi.org/10.1258/0956462 06779307621

[27] Balfe M, Brugha R, O'Donovan D, et al. Young women's decisions to accept chlamydia screening: influences of stigma and doctor-patient interactions. BMC public health. 2010; 10(1): 425. PMid:20642845 http://dx.doi.org/10.1186/1471-2458-10-425

[28] Hogan AH, Howell-Jones RS, Pottinger E, et al. “...they should be offering it": a qualitative study to investigate young peoples' attitudes towards chlamydia screening in GP surgeries. BMC Public Health. England; 2010; 616. PMid:20955570 